\title{
Sorafenib inhibits growth of hepatoma with hypoxia and hypoxia-driven angiogenesis in nude mice
}

\author{
F. $\mathrm{LI}^{1}, \mathrm{~F} . \mathrm{WANG}^{1}$, J. WU $\mathrm{WH}^{2, *}$ \\ ${ }^{1}$ Department of Interventional Therapy, First Affiliated Hospital of Dalian Medical University, Dalian 116001, China; ${ }^{2}$ Dalian Medical University, \\ Dalian 116001, China; ${ }^{3}$ Department of Radiology, Affiliated Zhongshan Hospital of Dalian University, Dalian 116001, China
}

${ }^{*}$ Correspondence: wujianlinvip@163.com

Received November 7, 2016 / Accepted March 8, 2017

\begin{abstract}
The study aimed to investigate the effects of sorafenib on growth of hepatoma with hypoxia and angiogenesis. Green fluorescent protein (GFP)-expressing SMMC-7721 hepatoma cells were established via transfection with a lentiviral vector carrying GFP. GFP-labelled cells were treated with $\mathrm{CoCl}_{2}$ for $24 \mathrm{~h}$ with or without pretreatment of sorafenib for $30 \mathrm{~min}$, and then injected subcutaneously into nude mice to induce hepatoma xenografts. This study used $16 \mathrm{BALB} / \mathrm{c}$ nude mice, which were divided into 4 groups: control group (GFP-labelled cells), $\mathrm{CoCl}_{2}$ group (GFP-labelled cells treated with $\mathrm{CoCl}_{2}$ ), $\mathrm{CoCl}_{2}$ plus sorafenib group (GFP-labelled cells pretreated with sorafenib and then treated with $\mathrm{CoCl}_{2}$ ) and $\mathrm{CoCl}_{2}$ plus sorafenib (cell+i.g.) group (GFP-labelled cells pretreated with sorafenib and then treated with $\mathrm{CoCl}_{2}$ ). After injection, $\mathrm{CoCl}_{2}$ plus sorafenib (cell+i.g.) group received intragastrical administration of sorafenib daily for 40 days. Tumor volume and weight were measured for each mouse. Cy5.5-annexinV and in vivo bioluminescence imaging were used for in vivo detection of cell apoptosis in tumor. Vascular endothelial growth factor (VEGF) and CD 34 were detected by immunohistochemistry. The results showed that, under the hypoxia condition induced by $\mathrm{CoCl}_{2}$, sorafenib pretreatment combined with intragastric administration of sorafenib more obviously suppressed tumor growth and decreased VEGF expression and MVD compared to sorafenib pretreatment alone, and induced cell apoptosis as well. Sorafenib pretreatment combined with intragastric administration is more effective than sorafenib pretreatment alone in the therapy of hepatoma.
\end{abstract}

Key words: VEGF, cobalt chloride, CD 34, tumor growth, in vivo bioluminescence imaging

Liver cancer is one of the most common cancers worldwide with the mortality rate ranking third among all cancers [1]. Hepatocellular carcinoma (HCC) is the primary type of liver cancer. Surgery removal is the standard therapy for hepatoma. Nevertheless, it is often not feasible because hepatoma is detected at late stage. Due to limited donors livers, option of liver transplantation is impossible for many patients. Therefore, investigation of the tumorigenesis of hepatoma is necessary for developing novel and effective medicines against hepatoma.

Hypoxia caused by uncontrollable cell proliferation is a common feature of hepatoma and strongly associated with aggressiveness of hepatoma [2]. Hypoxic microenvironment and angiogenesis have been intensively studied in molecular mechanisms. Cobalt chloride $\left(\mathrm{CoCl}_{2}\right)$ is a hypoxia-mimetic agent used to establish hypoxia model [3]. Dai Z J. et al. have reported that hypoxia stimulated by $\mathrm{CoCl}_{2}$ could effectively potentiate apoptosis of pancreatic cancer cells [4]. In addition, Zhang B O et al. have found that $\mathrm{CoCl}_{2}$ treatment inhibits proliferation of osteosarcoma cells [5]. However, there is evidence that hypoxia can decrease apoptotic cell death [6] and promote cell HCC cellular growth [7]. These evidences suggest that there remain controversies concerning the exact effect of hypoxia on cancer development. Furthermore, it has been reported that hypoxia caused by cobalt chloride modulates the expression of ascular endothelial growth factor (VEGF) by regulating hypoxia inducible factor- $1 \alpha$ (HIF- $1 \alpha)$ and insulinlike growth factor I (IGF-1) [8].

Sorafenib is an approved drug for treatment of advanced hepatocellular carcinoma (HCC) $[9,10]$. It inhibits various tyrosine protein kinases, such as VEGF receptors and plateletderived growth (PDGF) receptors [11]. Moreover, Satoshi S et al. have found that sorafenib administration induces autophagy contributing to the antitumor activity of sorafenib in HCC $[12,13]$. Sorafenib may restrain proliferation of HCC cells via downregulating PI K/AKT pathway [14]. Besides, it has been proved that sorafenib inhibits angiogenesis through 
regulating extracellular signal-regulated kinase (ERK) pathway in HCC [15]. However, there are few studies focused on the impact of sorafenib on hepatoma cells treated with $\mathrm{CoCl}_{2} \mathrm{mim}$ icking hypoxia. Although Ming X et al. have provided in vitro evidence that sorafenib suppresses $\mathrm{CoCl}_{2}$-induced tumor cell invasiveness and induce cell apoptosis in hepatoma cells [16]. In vivo studies are needed to unravel the effect of Sorafenib on hypoxia-treated hepatoma growth and angiogenesis.

In this study, we constructed green fluorescent protein (GFP)-expressing SMMC-7721 hepatoma cells, which were treated with $\mathrm{CoCl}_{2}$ to establish hypoxia model. In order to investigate the impact of sorafenib and $\mathrm{CoCl}_{2}$ on tumor growth, GFP-expressing SMMC-7721 cells treated with or without $\mathrm{CoCl} 2$ or sorafenib were injected subcutaneously into nude mice to form tumors. In vivo bioluminescence imaging was used for in vivo detection of tumor cell apoptosis. VEGF and cluster of differentiation (CD)34 expression (microvessel density) were detected immuno- histologically to reflect the effect of sorafenib and $\mathrm{CoCl}_{2}$ on tumor angiogenesis.

\section{Materials and methods}

Cell culture. SMMC-7721 hepatoma cells were purchased from Shanghai cell bank of Chinese academy of sciences and cultured in Dulbecco's modification of Eagle's medium Dulbecco (DMEM, GIBCO, NY, USA) medium supplemented with $10 \%$ fetal bovine serum (FBS, GIBCO, NY, USA) in a $5 \%$ $\mathrm{CO}_{2}$ incubator at $37^{\circ} \mathrm{C}$. The study was approved by animal care committee of our hospital.

Lentivirus infection. SMMC-7721 cells were seeded in a six-well plate $\left(2 \times 10^{5}\right.$ cells/plate $)$. The cells were cultured in complete medium and transfected with a lentiviral vector (LV) carrying green fluorescent protein (GFP) of our lab for $24 \mathrm{~h}$. The cells were observed under a fluorescence microscope (Olympus, Tokyo, Japan). Subsequently, the cells underwent selection with $4 \mu \mathrm{g} / \mathrm{mL}$ puromycin (Sigma, CA, USA). After 3 passages, the GFP-expressing cells were used for further experiments.

Cell treatment. GFP-labelled SMMC-7721 cells were randomly divided into 3 groups: control group, $\mathrm{CoCl}_{2}$ group and $\mathrm{CoCl}_{2}+$ sorafenib group. Cells in the $\mathrm{CoCl}_{2}+$ sorafenib group were pretreated with $4 \mu \mathrm{m} / \mathrm{L}$ sorafenib for $30 \mathrm{~min}$ and then treated with $150 \mu \mathrm{m} / \mathrm{L} \mathrm{CoCl}_{2}$ (Sigma, CA, USA) for $24 \mathrm{~h}$. The $\mathrm{CoCl}_{2}$ group was pretreated with DMSO (vehicle of sorafenib, Sigma, CA, USA) for $30 \mathrm{~min}$, and then incubated with 150 $\mu \mathrm{m} / \mathrm{L} \mathrm{CoCl}_{2}$ (Sigma, CA, USA) for $24 \mathrm{~h}$. The control group was incubated with complete medium for the same duration. These cells were then used for animal experiments.

Animal experiments. A total of 16 male SPF (specific pathogen free) $\mathrm{BALB} / \mathrm{c}$ nude mice (4-week old) were provided by the experimental animal center of Shanghai Jiao Tong University. These mice were divided into 4 groups $(n=4)$ : control group, $\mathrm{CoCl}_{2}$ group, $\mathrm{CoCl}_{2}$ plus sorafenib group and $\mathrm{CoCl}_{2}$ plus sorafenib (cell+i.g.) group. Mice in the control group received a subcutaneous injection of control GFP-labelled
SMMC-7721 cells $\left(2 \times 10^{7} / \mathrm{ml}\right)$ in $0.2 \mathrm{ml}$ serum-free medium. Mice in the $\mathrm{CoCl}_{2}$ group were subcutaneously injected with $0.2 \mathrm{ml}$ cell suspension made of $\mathrm{CoCl} 2$ treated-GFP- labelled SMMC-7721 cells. Mice both in the $\mathrm{CoCl}_{2}$ plus sorafenib group and $\mathrm{CoCl}_{2}$ plus sorafenib (cell+i.g.) group received a subcutaneous injection of GFP-labelled SMMC-7721 cells (2 $\times 10^{7} / \mathrm{ml}$ ) treated with sorafenib and $\mathrm{CoCl}_{2}$ in $0.2 \mathrm{ml}$ serumfree medium. Moreover, the mice in the $\mathrm{CoCl} 2$ plus sorafenib (cell+i.g.) group then were administrated intragastrically with sorafenib $(60 \mathrm{mg} / \mathrm{kg})$ daily for 40 days. The growth of subcutaneous tumors and body weight were evaluated by measurement of the length and width of tumors using vernier gauges at 2 days, 9 days, 16 days, 23 days, 30 days and 40 days after injection. Tumor size was calculated as follow: length $x$ width $^{2} \times 0.4$. At the end of the experiments ( 40 days), the mice were sacrificed with carbon dioxide and the tumor weight of each mouse was weighed.

In vivo bioluminescence imaging. After anaesthetized by isoflurane inhalation, the mice bearing subcutaneous GFP-labelled SMMC-7721 cells tumors in different groups were placed supine in the IVIS ${ }^{\circledR}$ chamber and visualized by in vivo bioluminescence imaging (IVIS Lumina II; Caliper Life Sciences, Hopkinton, MA; $\lambda_{\text {exc }}: 480 \mathrm{~nm}, \lambda_{\mathrm{em}}: 520 \mathrm{~nm}$ ). Light emission was measured using Living Image software. The resulting pseudo-color images stood for the spatial distribution of photon counts within the tumor. Identical illumination settings were applied in obtaining all images.

Annexin V [17] (Sigma, St. Louis, Missouri, USA) were conjugated to Cy5.5 in $0.1 \mathrm{M}$ sodium carbonate/bicarbonate buffer ( $\mathrm{pH}$ 9.3). Briefly, $2 \mu \mathrm{g}$ Cy5.5-annexinV were injected into each mice intravenously via a tail vein. After $24 \mathrm{~h}$, the mice were anesthetized with isoflurane and visualized by in vivo bioluminescence imaging $\left(\lambda_{\text {exc }}: 660 \mathrm{~nm}\right)$. Fluorescence images were obtained and average fluorescent value in select regions of interest (ROI) were quantified with IVIS ${ }^{\circledR}$ software.

IHC for detection of VEGF and CD34. VEGF and CD34 in tumor tissues were detected by immunohistochemistry. Subcutaneous tumor were removed from mice and washed with pre-cooled PBS buffer and fixed in $10 \%$ paraformaldehyde for $24 \mathrm{~h}$. The tissue samples were dehydrated via gradient ethanol immersion, clarified with dimethylbenzene and embedded in paraffin. The paraffin-embedded tissue samples were cut into sections at $6 \mu \mathrm{m}$. After dewaxing using a xylene-ethanol series and antigen retrieval, the tissue samples were incubated with $3 \% \mathrm{H}_{2} \mathrm{O}_{2}$ for 10 min, blocked with goat serum for $1 \mathrm{~h}$. Subsequently, the tissue sections were incubated with primaries antibodies (Santa cruz, Argentina; mouse monoclonal antibody; VEGF, sc-53462; CD 34, sc-74499) over night at $4^{\circ} \mathrm{C}$, and incubated with secondary antibody (peroxidase AffiniPure Goat Anti-Rabbit IgG $(\mathrm{H}+\mathrm{L})$ 111-035-003, Jackson ImmunoResearch Laboratories, West Grove, $\mathrm{PA}$ ) at $37^{\circ} \mathrm{C}$ for $1 \mathrm{~h}$. Finally, the tissue sections were stained using diaminobenzidine tetrahydrochloride (Golden Bridge Biological Technology, China). Brown staining was considered positive. Images were analyzed using Image-Pro 
A

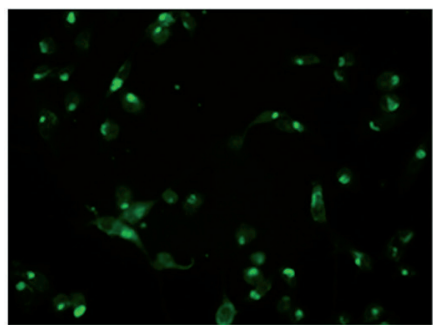

B

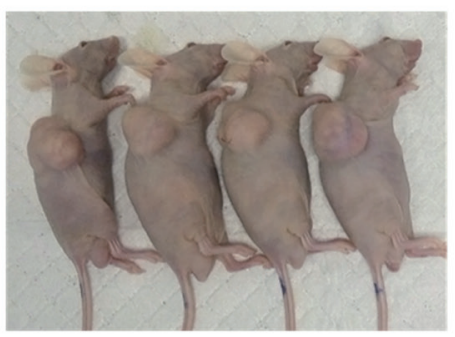

$\mathrm{CoCl}_{2}+$ sorafenib

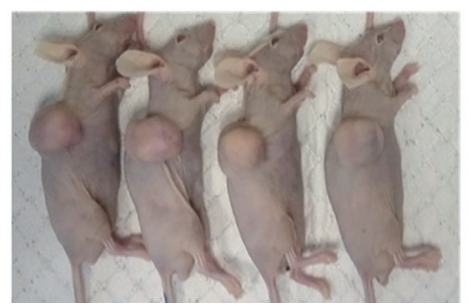

$\mathrm{CoCl}_{2}$

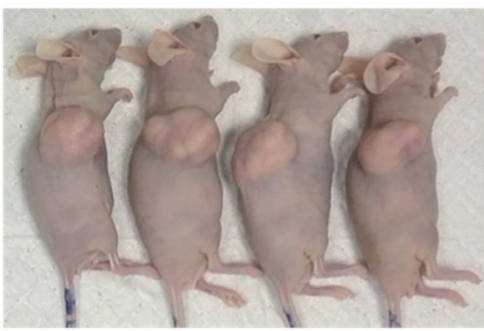

$\mathrm{CoCl}_{2}+$ sorafenib (cell and i.g.)

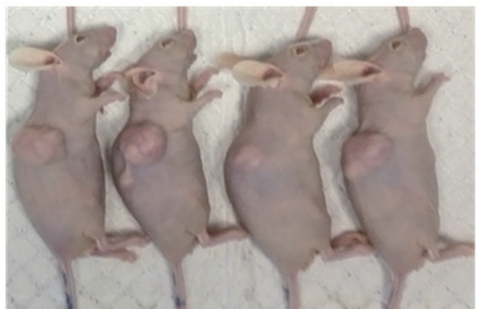

Figure 1. GFP-expressing SMMC-7721 cells after 3 passages (A) and the tumor size of mice in different groups after the mice were sacrificed at the end of the experiments (40 days)(B).

plus 6.0 image analysis software. Five view fields of each slice was randomly selected and observed under a light microscope (CKX31, Olympus, Center Valley, PA, USA).

Statistical analysis. Data were expressed as mean \pm SEM. Statistical analysis were performed using SPSS software (SPSS Inc., Chicago, USA). The differences between groups were analyzed by one-way analysis of variance (ANOVA) followed by the post hoc least significant difference test. $P$-value $<0.05$ was considered significant.

\section{Results}

GFP-expressing SMMC-7721 hepatoma cells were established and sorafenib suppressed growth of hepatoma with hypoxia in nude mice. As shown in Figure 1A, GFPexpressing SMMC-7721 cells were successfully established. GFP-expressing SMMC-7721 cells were injected subcutaneously into nude mice for establishment of a hepatoma transplantation model. These mice were divided into 4 groups $(\mathrm{n}=4)$ : control group, $\mathrm{CoCl}_{2}$ group, $\mathrm{CoCl}_{2}$ plus sorafenib group and $\mathrm{CoCl}_{2}$ plus sorafenib (cell+i.g.) group. Figure $1 \mathrm{~B}$ displayed the tumor size of mice in different groups after the mice were sacrificed at the end of the experiments (40 days). In addition, tumor volume, tumor weight and body weight were measured at 2 days, 9 days, 16 days, 23 days, 30 days and 40 days. As shown in Figure 2 A, tumor volume were significantly decreased in the $\mathrm{CoCl}_{2}$ plus sorafenib group and $\mathrm{CoCl}_{2}$ plus sorafenib (cell+i.g.) group relative to the control group $(p<0.05)$. The $\mathrm{CoCl}_{2}$ plus sorafenib (cell+i.g.) group had further smaller tumor than the $\mathrm{CoCl}_{2}$ plus sorafenib group $(p<0.05)$. The difference between the control group and the $\mathrm{CoCl}_{2}$ group was not significant $(\mathrm{p}>0.05)$. With regard to tumor weight (Figure $2 \mathrm{~B}$ ), only the $\mathrm{CoCl}_{2}$ plus sorafenib (cell+i.g.) group had markedly decreased tumor weight compared to the control group $(\mathrm{p}<0.01)$. Tumor weight did not significantly differ between control group, $\mathrm{CoCl}_{2}$ group and $\mathrm{CoCl}_{2}$ plus sorafenib group. Additionally, there was no significant difference in body weight between the mice in 4 groups (Figure 2C, $p>0.05$ ).

Sorafenib pretreatment and intragastric administration induced cell apoptosis in tumor under hypoxia condition. In vivo imaging revealed that fluorescence intensity of mice in difference groups (Figure 3A). Moreover, fluorescently labeled annexin V (Cy5.5-annexinV) was used as a marker to detect apoptotic cells in tumor in vivo. As shown in Figure 3B-C, fluorescence intensity in the $\mathrm{CoCl}_{2}$ plus sorafenib (cell+i.g.) group were obviously higher than that in the control group, $\mathrm{CoCl}_{2}$ group and $\mathrm{CoCl}_{2}$ plus sorafenib group $(p<0.05)$. The differences between control group, $\mathrm{CoCl}_{2}$ group and $\mathrm{CoCl}_{2}$ plus sorafenib group did not achieve significance $(p>0.05)$. These observations suggest that treatment of $\mathrm{CoCl}_{2}$ plus sorafenib (cell+i.g.) promotes cell apoptosis in tumor in vivo.

Sorafenib pretreatment and intragastric administration inhibited angiogenesis under hypoxia condition. Microvessel density (MVD) is regarded as a surrogate marker for tumor angiogenesis and is detected by immunohistochemically by 

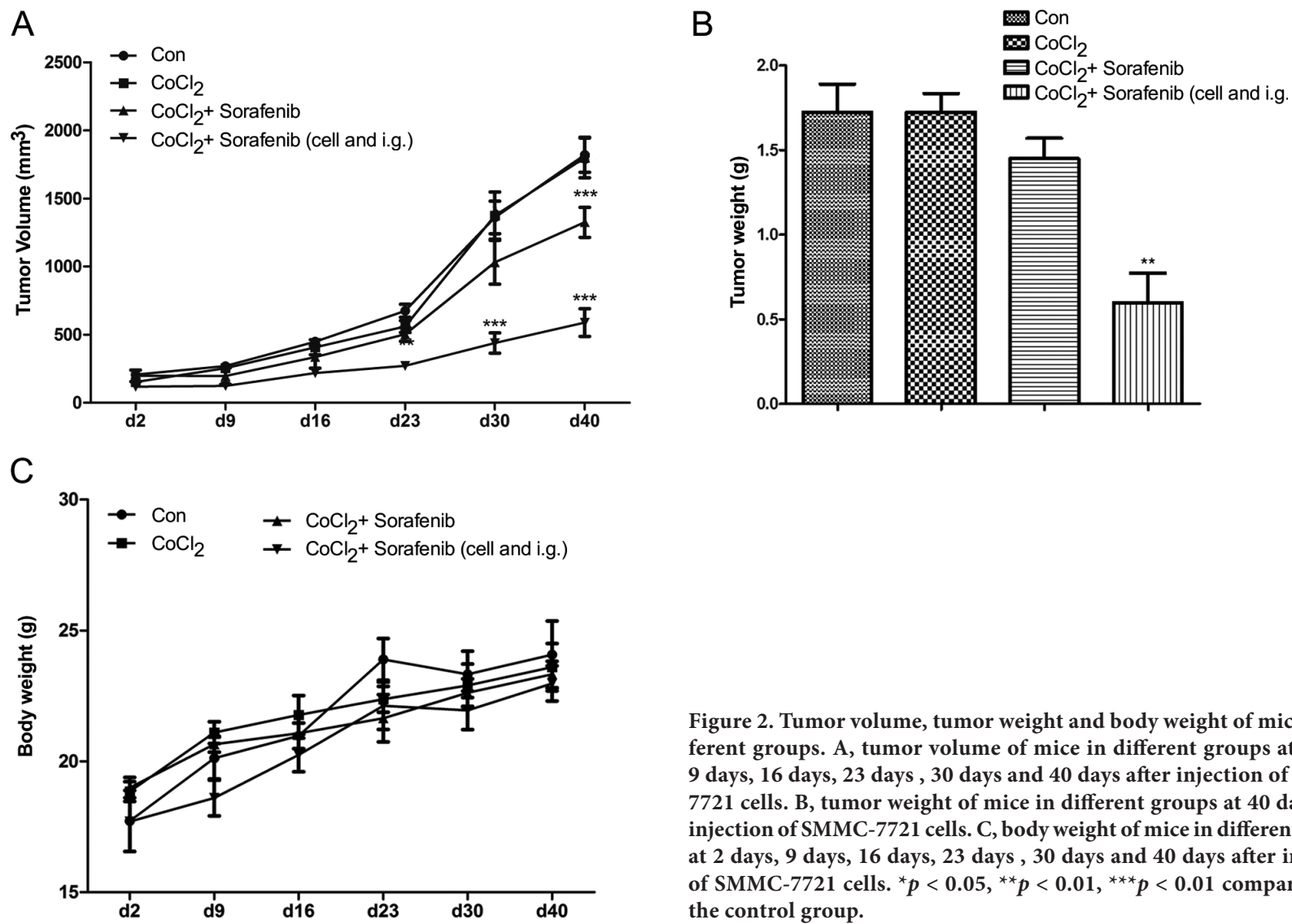

Figure 2. Tumor volume, tumor weight and body weight of mice in different groups. A, tumor volume of mice in different groups at 2 days, 9 days, 16 days, 23 days , 30 days and 40 days after injection of SMMC7721 cells. $B$, tumor weight of mice in different groups at 40 days after injection of SMMC-7721 cells. C, body weight of mice in different groups at 2 days, 9 days, 16 days, 23 days, 30 days and 40 days after injection of SMMC-7721 cells. ${ }^{\star} p<0.05,{ }^{* *} p<0.01,{ }^{* * *} p<0.01$ compared with the control group.
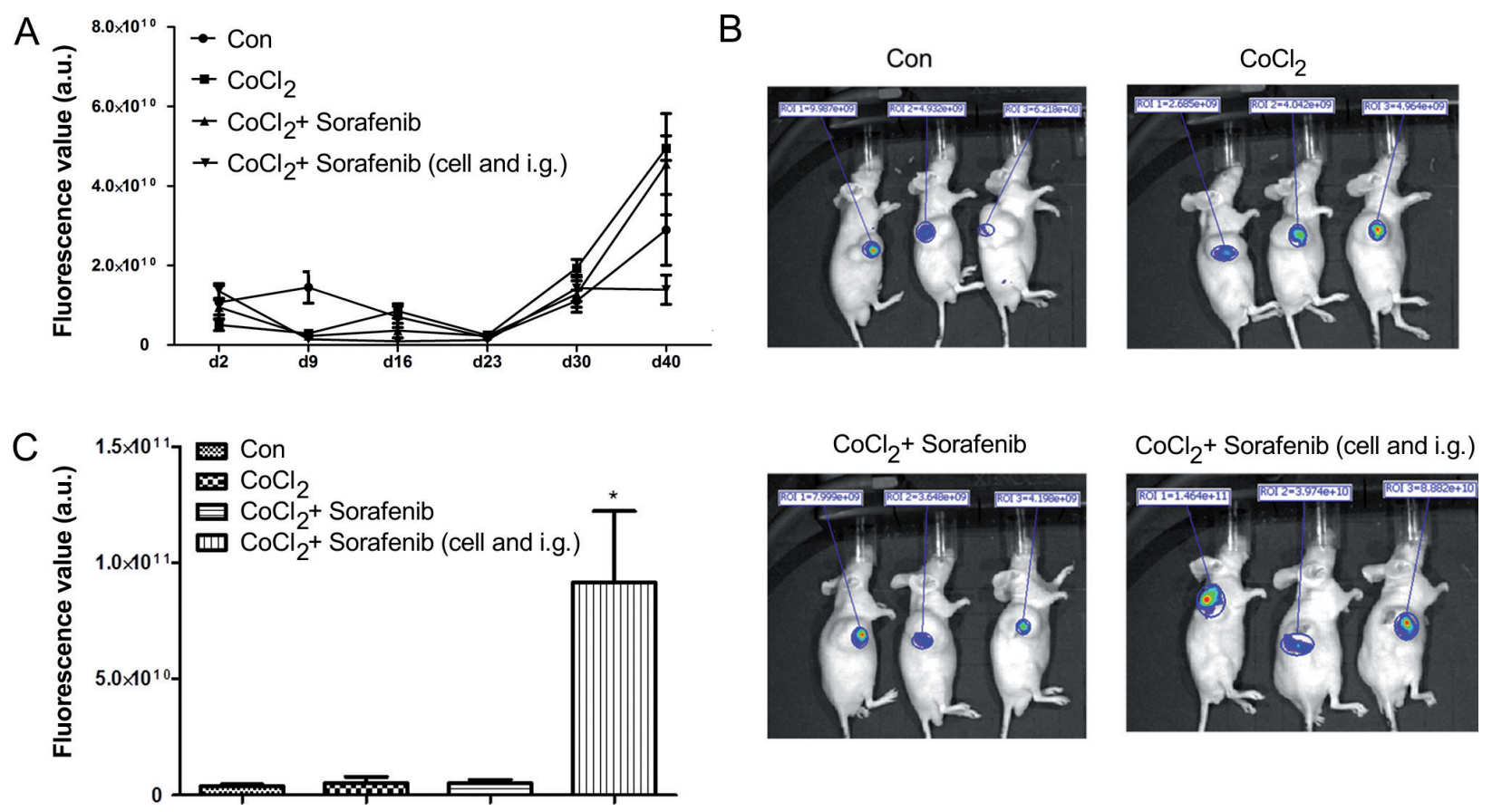

Figure 3. Whole Animal in Vivo Imaging. A, fluorescence intensity of mice in difference groups. GFP-expressing SMMC-7721 cells after different treatments are injected into nude mice of different groups to induce hepatoma xenografts. B-C Fluorescence value of Cy5.5-annexinV detected by in vivo bioluminescence imaging of mice in different groups. ${ }^{*} p<0.05$ compared with the control group. 


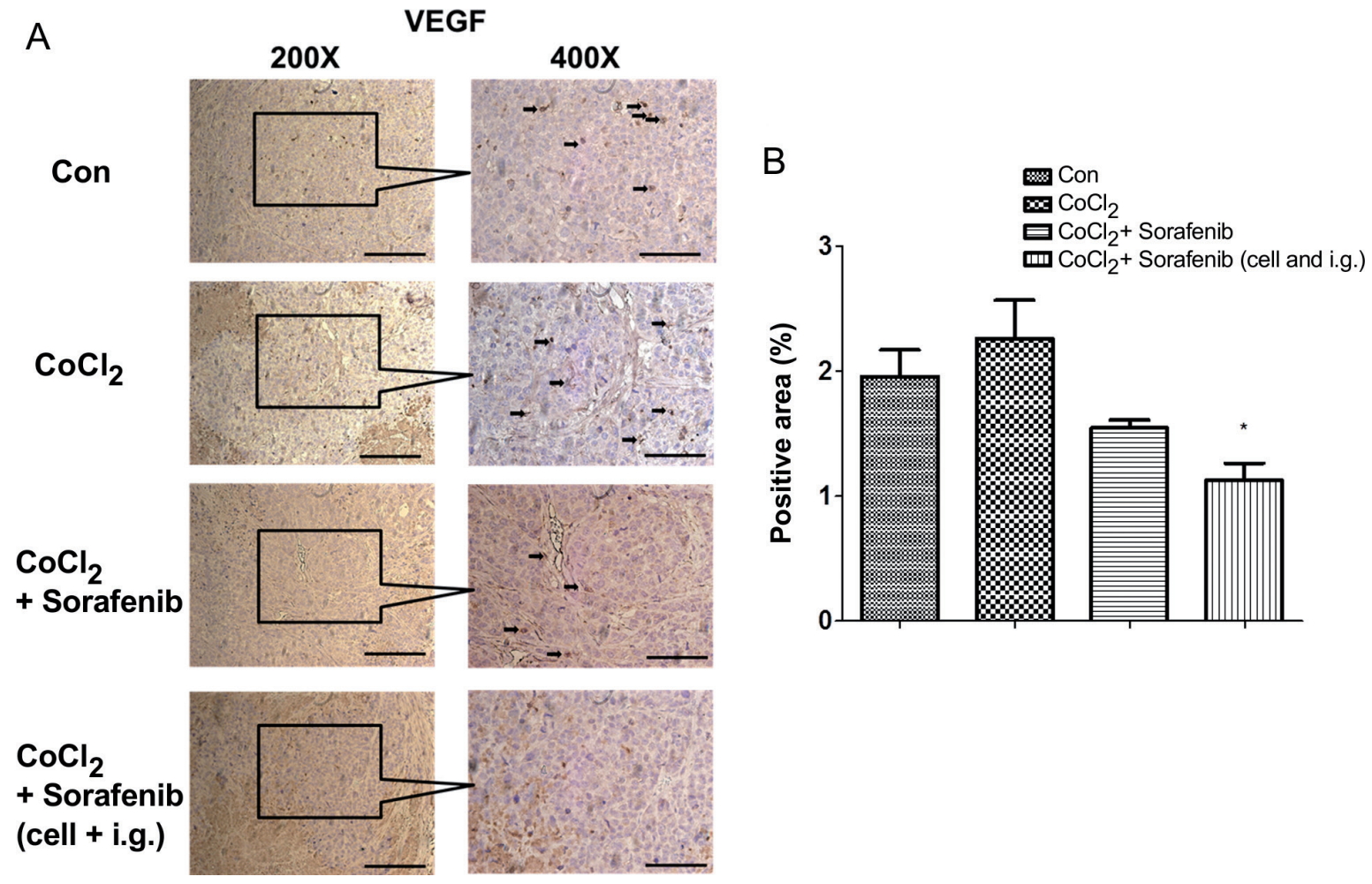

Figure 4. VEGF expression detected by immunohistochemistry. A, immunohistochemical staining images of VEGF in different groups. B, quantitative analysis of VEFG immunohistochemical staining in different groups. ${ }^{*} p<0.05$ compared with the control group.

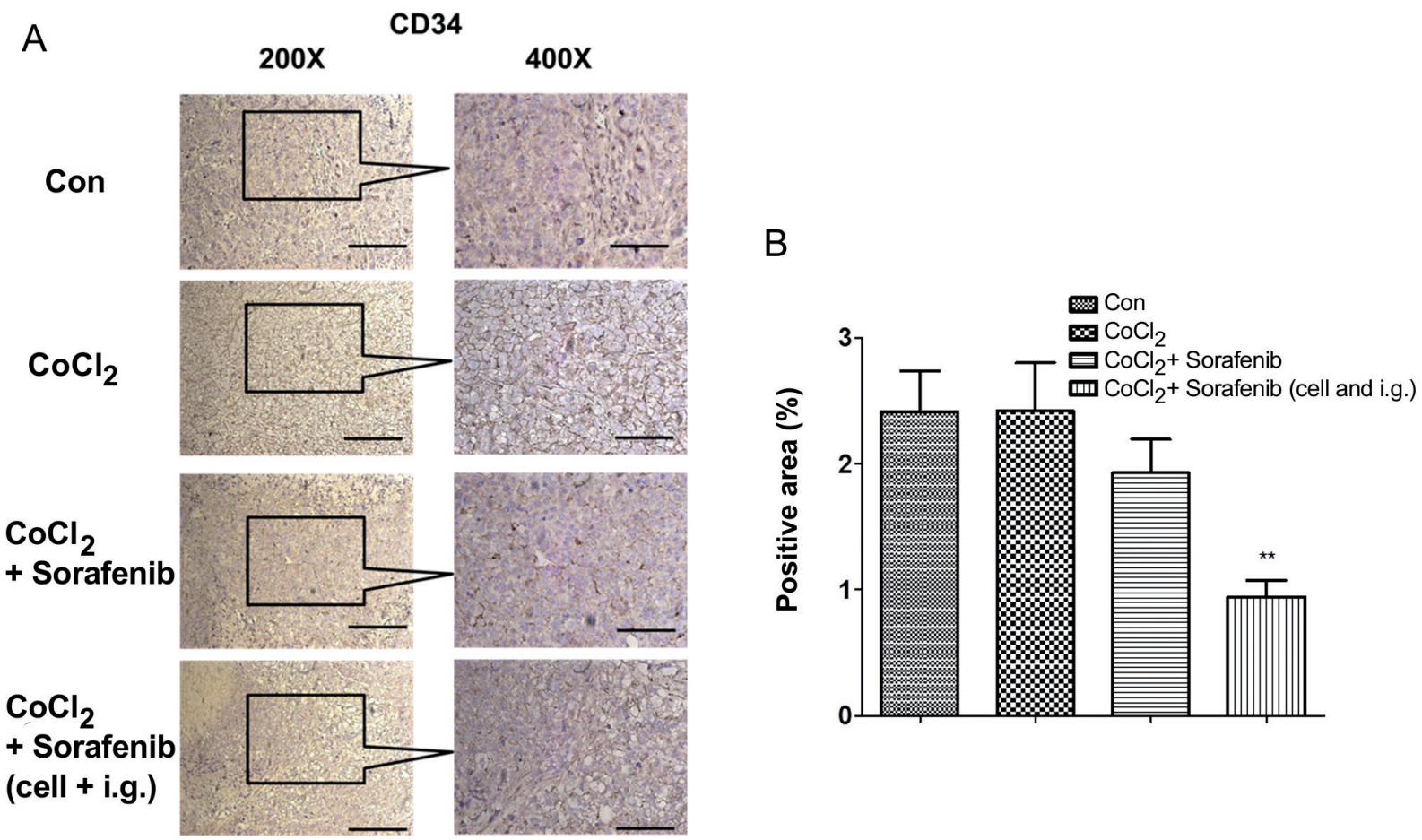

Figure 5. CD 34 expression detected by immunohistochemistry. A, immuno- histochemical staining images of CD34 in different groups. B, quantitative analysis of CD34 immunohistochemical staining in different groups. ${ }^{\star *} p<0.01$ compared with the control group. 
antibody against CD $34[18,19]$. VEGF is a angiogenesis stimulating signal in HCC [20]. Expression of VEGF and CD34 was measured by IHC to evaluate the impact of $\mathrm{CoCl}_{2}$ and sorafenib on tumor-related angiogenesis. Compared with control group, positive staining area of VEGF was remarkably decreased in the $\mathrm{CoCl}_{2}$ plus sorafenib (cell+i.g.) group $(p<$ 0.05 , Figure 4). However, the differences between the control group, $\mathrm{CoCl}_{2}$ group and $\mathrm{CoCl}_{2}$ plus sorafenib group did not reach significance $(p>0.05)$.

Similarly, $\mathrm{CoCl}_{2}$ plus sorafenib (cell+i.g.) group had obviously decreased positive staining area of CD34 than the control group ( $p>0.05$, Figure 5). Nonetheless, positive staining area of CD34 was not significantly different between the control group, $\mathrm{CoCl}_{2}$ group and $\mathrm{CoCl}_{2}$ plus sorafenib group $(p>0.05)$.

\section{Discussion}

Hepatoma remains a major threat to the lives of people. Hypoxia caused by uncontrollable proliferation of tumor cells results in hypoxia, which induces angiogenesis. The study was centered on the influence of sorafenib on hepatoma xenografts induced by hepatoma cells treated with $\mathrm{CoCl}_{2}$ in nude mice. One feature of the study was that GFP-expressing SMMC7721 hepatoma cells were established to induce hepatoma xenografts in nude mice for in vivo bioluminescence imaging. Moreover, fluorescently labeled annexin V (Cy5.5-annexinV) was used to detect cell apoptosis in vivo. The study delivers in vivo evidence that sorafenib suppresses growth of hepatoma with hypoxia and hypoxia-driven angiogenesis. Furthermore, sorafenib pretreatment combined with continued intragastric administration exerted a stronger inhibitory effect on growth of hepatoma xenografts in nude mice than sorafenib pretreatment alone and potentiated cell apoptosis.

Sorafenib is safe and efficacious for patients with advanced HCC [21]. Recently, Ming X et al. have reported that sorafenib treatment inhibits cell proliferation and strengthens apoptosis in hepatoma cells in vitro [16]. In consistence with the finding, the present study found that sorafenib pretreatment suppressed growth of tumor induced by hypoxia-treated SMMC-7721 cells in nude mice. Moreover, compared with sorafenib pretreatment alone, sorafenib pretreatment combined with intragastric administration of sorafenib appeared to exert a stronger inhibitory effect on tumor growth and induced apoptotic death of tumor cells. These findings indicate that sorafenib pretreatment in conjunction with intragastric administration of sorafenib is more effective than sorafenib pretreatment alone. Continued administration of sorafenib is important for anticancer therapy of hepatoma cells in a hypoxic state.

It has been established that cobalt chloride-mimicking hypoxia leads to increased expression of VEGF [22]. Moreover, cobalt chloride treatment stimulates HIF-1a/VEGFA pathway [16], which is inhibited by sorafenib [8]. Similarly, the study also found that cobalt chloride treatment resulted in increased VEFG expression and MVD. Sorafenib pretreatment alone inhibited expression of VEGF and MVD induced by cobalt chloride. Moreover, a combination of sorafenib pretreatment and intragastric administration of sorafenib further decreased VEGF expression and MVD to a lower level in comparison with sorafenib pretreatment alone. These results reveal that sorafenib inhibits hypoxia-driven angiogenesis in hepatoma. Sorafenib pretreatment and intragastric administration of sorafenib appeares to exert a stronger inhibitory impact on angiogenesis. Sorafenib may inhibit tumor growth via disturbing hypoxia-driven angiogenesis.

It is a preliminary study. We did not provide data about whether sorafenib treatment alone could lead to tumor growth suppression, which is a limitation of our study. Performing sorafenib treatment alone will provide a strong evidence to support the inhibitory effect of sorafenib on hepatoma cells under hypoxic condition. Moreover, considering the findings obtained from previous studies [12-15], more experiments are needed to uncover the molecular mechanisms behind the inhibitory effect of sorafenib on hepatoma cells under hypoxic condition. In addition, only 4 mice/group were used for in vivo study. The small sample size will influence the convince of our results. Thus, at least 6 mice/ group should be used for in vivo study in the future. Besides, there was no effect of Cocl2-induced hypoxia on hepatoma in our study. The exact effect of hypoxia on cancer development remains elusive and need to be further investigated.

\section{Conclusion}

The study suggests that sorafenib inhibits growth of hepatoma with hypoxia and hypoxia-driven angiogenesis. Sorafenib pretreatment combined with intragastric administration induces hepatoma cell apoptosis and is more effective to suppress tumor growth and hypoxia-induced angiogenesis than sorafenib pretreatment alone. The study provides added insights into the effect of sorafenib on hepatoma with hypoxia. Further studies are warranted to verify and expand the findings of this study.

Acknowledgments: This work was supported by the Science and Technology Program of Dalian (No.2015E12SF154).

\section{References}

[1] MCGUIRE S. World Cancer Report 2014. Geneva, Switzerland: World Health Organization, International Agency for Research on Cancer, WHO Press, 2015. Adv Nutr 2016; 7: 418-419. https://doi.org/10.3945/an.116.012211

[2] HIRATSUKA S. Vasculogenensis, angiogenesis and special features of tumor blood vessels. Front Biosci (Landmark Ed) 2011; 16: 1413-1427. https://doi.org/10.2741/3796

[3] BAE S, JEONG HJ, CHA HJ, KIM K, CHOI YM et al. The hypoxia-mimetic agent cobalt chloride induces cell cycle arrest and alters gene expression in U266 multiple myeloma cells. Int J Mol Med 2012; 30: 1180-1186. 
[4] DAI ZJ, GAO J, MA XB, YAN K, LIU XX et al. Up-regulation of hypoxia inducible factor- $1 \hat{\mathrm{I}} \pm$ by cobalt chloride correlates with proliferation and apoptosis in PC-2 cells. J Exp Clin Cancer Res 2012; 31: 28. https://doi.org/10.1186/1756-9966$\underline{31-28}$

[5] ZHANG B, GUO W, YU L, WANG F, XU Y et al. Cobalt chloride inhibits tumor formation in osteosarcoma cells through upregulation of HIF-1a. Oncol Lett 2013; 5: 911-916.

[6] ARDYANTO TD, OSAKI M, TOKUYASU N, NAGAHAMA Y, ITO H. CoCl2-induced HIF-1 alpha expression correlates with proliferation and apoptosis in MKN-1 cells: a possible role for the PI3K/Akt pathway. Int J Oncol 2006; 29: 549-555.

[7] GWAK GY, YOON JH, KIM KM, LEE HS, CHUNG JW et al. Hypoxia stimulates proliferation of human hepatoma cells through the induction of hexokinase II expression. J Hepatol 2005; 42: 358-364. https://doi.org/10.1016/j. jhep.2004.11.020

[8] LIU Q, XU Z1, MAO S1, CHEN W1, ZENG R et al. Effect of hypoxia on hypoxia inducible factor-1 $\alpha$, insulin-like growth factor I and vascular endothelial growth factor expression in hepatocellular carcinoma HepG2 cells. Oncol Lett 2015; 9: 1142-1148. https://doi.org/10.3892/ol.2015.2879

[9] GAUTHIER A, HO M. Role of sorafenib in the treatment of advanced hepatocellular carcinoma: An update. Hepatol Res 2013; 43: 147-154. https://doi.org/10.1111/j.1872034X.2012.01113.X

[10] LLOVET JM, RICCI S, MAZZAFERRO V, HILGARD P, GANE E et al. Sorafenib in advanced hepatocellular carcinoma. N Engl J Med 2008; 359: 378-390. https://doi.org/10.1056/ NEJMoa0708857

[11] WILHELM SM, ADNANE L, NEWELL P, VILLANUEVA A, LLOVET JM et al. Preclinical overview of sorafenib, a multikinase inhibitor that targets both Raf and VEGF and PDGF receptor tyrosine kinase signaling. Mol Cancer Ther 2008; 7: 3129-3140. https://doi.org/10.1158/1535-7163.MCT-08-0013

[12] SHIMIZU S, TAKEHARA T, HIKITA H, KODAMA T, TSUNEMATSU H et al. Inhibition of autophagy potentiates the antitumor effect of the multikinase inhibitor sorafenib in hepatocellular carcinoma. Int J Cancer 2012; 131: 548-557. https://doi.org/10.1002/ijc.26374

[13] SHI YH, DING ZB, ZHOU J, HUI B, SHI GM et al. Targeting autophagy enhances sorafenib lethality for hepatocellular carcinoma via ER stress-related apoptosis. Autophagy 2011; 7: 1159-1172. https://doi.org/10.4161/auto.7.10.16818
[14] GEDALY R, ANGULO P, HUNDLEY J, DAILY MF, CHEN $\mathrm{C}$ et al. PKI-587 and sorafenib targeting PI3K/AKT/mTOR and Ras/Raf/MAPK pathways synergistically inhibit HCC cell proliferation. J Surg Res 2012; 176: 542-548. https://doi. org/10.1016/j.jss.2011.10.045

[15] LIU L, CAO Y, CHEN C, ZHANG X, MCNABOLA A et al. Sorafenib blocks the RAF/MEK/ERK pathway, inhibits tumor angiogenesis, and induces tumor cell apoptosis in hepatocellular carcinoma model PLC/PRF/5. Cancer Res 2006; 66: 11851-11858. https://doi.org/10.1158/0008-5472.CAN-06$\underline{1377}$

[16] XU M, ZHENG YL, XIE XY, LIANG JY, PAN FS et al. Sorafenib blocks the HIF-1 $\alpha$ /VEGFA pathway, inhibits tumor invasion, and induces apoptosis in hepatoma cells. DNA Cell Biol 2014; 33: 275-281. https://doi.org/10.1089/dna.2013.2184

[17] YANG SK, ATTIPOE S, KLAUSNER AP, TIAN R, PAN D et al. In Vivo Detection of Apoptotic Cells in the Testis Using Fluorescence Labeled Annexin V in a Mouse Model of Testicular Torsion. J Urol 2006; 176: 830-835. https://doi. org/10.1016/j.juro.2006.03.073

[18] DING S, LI C, LIN S, YANG Y, LIU D et al. Comparative evaluation of microvessel density determined by CD34 or CD105 in benign and malignant gastric lesions. Human Pathol 2006; 37: 861-866. https://doi.org/10.1016/j.humpath.2006.02.006

[19] DE LA TAILLE A, KATZ AE, BAGIELLA E, BUTTYAN R, SHARIR $S$ et al. Microvessel density as a predictor of PSA recurrence after radical prostatectomy. A comparison of CD34 and CD31. Am J Clin Pathol 2000; 113: 555-562. https://doi. org/10.1309/02W2-KE50-PKEF-G2G4

[20] FINN RS, ZHU AX. Targeting angiogenesis in hepatocellular carcinoma: focus on VEGF and bevacizumab. Expert Rev Anticancer Ther 2009; 9: 503-509. https://doi.org/10.1586/ era.09.6

[21] BRUIX J, RAOUL JL, SHERMAN M, MAZZAFERRO V, BOLONDI $L$ et al. Efficacy and safety of sorafenib in patients with advanced hepatocellular carcinoma: subanalyses of a phase III trial. J Hepatol 2012; 57: 821-829. https://doi.org/10.1016/j. jhep.2012.06.014

[22] LIU XH, KIRSCHENBAUM A, YAO S, STEARNS ME, HOLLAND JF et al. Upregulation of vascular endothelial growth factor by cobalt chloride-simulated hypoxia is mediated by persistent induction of cyclooxygenase- 2 in a metastatic human prostate cancer cell line. Clin Exp Metastasis 1999; 17: 687-694. https://doi.org/10.1023/A:1006728119549 